\title{
Improved Performance of DFIG-generators for Wind Turbines Variable-speed
}

\author{
Ihedrane Yasmine ${ }^{1}$, El Bekkali Chakib ${ }^{2}$, Bossoufi Badre ${ }^{3}$ \\ ${ }^{1,2}$ LISTA Laboratory, Faculty of Sciences Dhar El Mahraz.University Sidi Mohammed Ben Abdellah, Fez, Morocco \\ ${ }^{3}$ Laboratory GEM, Higher School of Technology, EST-Oujda,University of Mohammed I, Oujda, Morocco
}

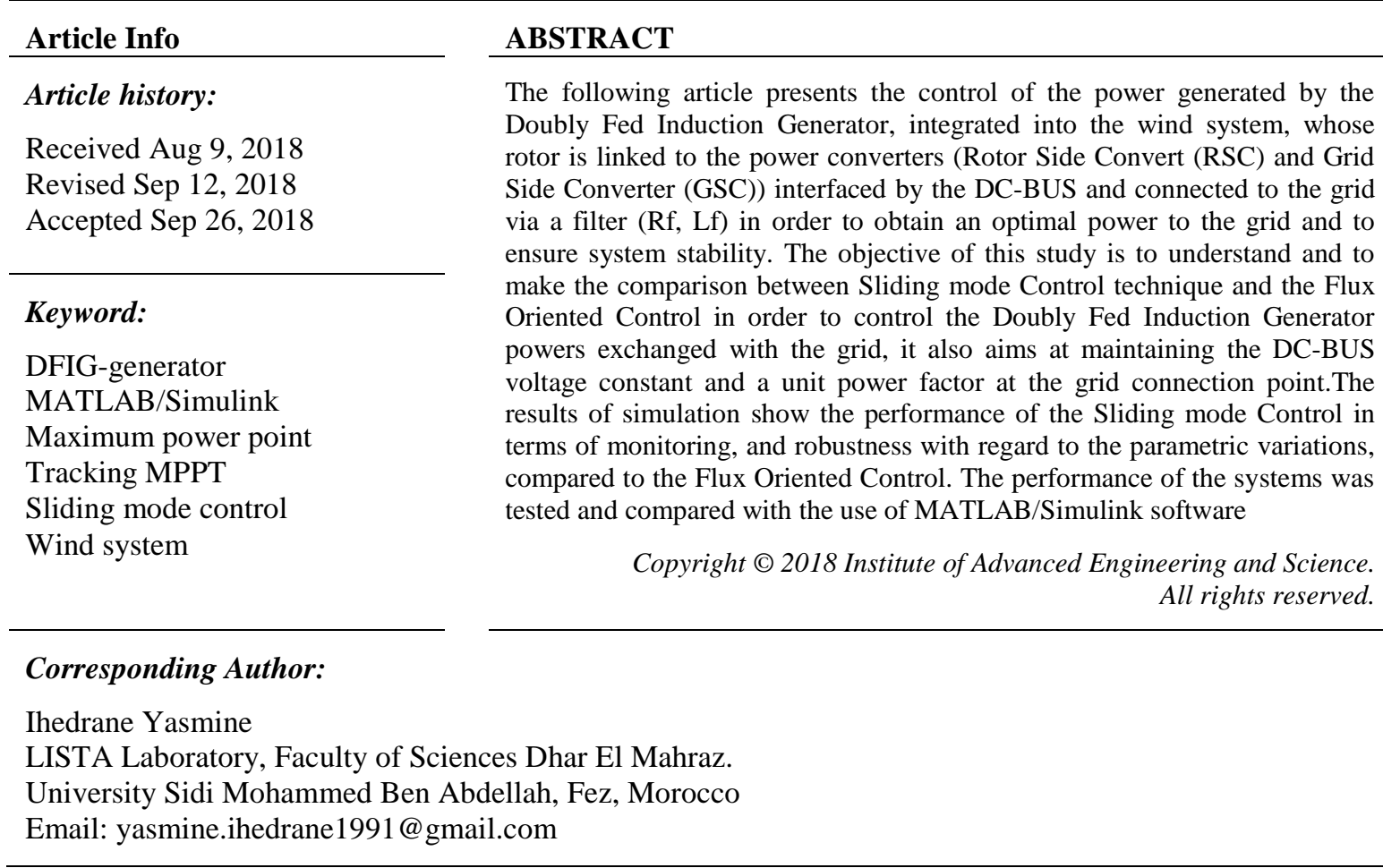

\section{INTRODUCTION}

Recently, energy demands have grown strongly, while sources of sickle fuels have decreased enormously. For this reason, the development and exploitation of renewable energies have grown extremely. Among these sources, we find the wind energy which has been the subject of several researches in electrical and electromechanical engineering to improve the quality of the produced energy.Currently, wind turbine systems with variable speed based on the Doubly Fed Induction Generator as shown in Figure 1 are the most commonly used in wind farms because they allow the operation on a speed range of $\pm 30 \%$ around the synchronous speed, thanks to the dimensioning of the three-phase static converters for a part of the nominal power $\pm 30 \%$, which makes it possible to reduce losses in electronic power components and the overall system increase.Therefore, not only does energy production depend on the way in which the converters are controlled but also on the DFIG generator. The rotor side converter "RSC"controls the reactive and active power of the DFIG whereas the grid side converter "GSC" controls the DC-LINK voltage and power factor.The major problem of the Doubly Fed Induction Generator is that it is characterized by a non-linear, multi-variable mathematical model with a heavy coupling between input variables (i.e.) it is not possible to independently control the voltage or the current [1].In order to control this machine, many works of implementation which use approaches based on linear models have been applied, but the approach by linear controller has rapidly showed its limits. That is why this researches are turned towards the nonlinear techniques to increase the robustness and the precision of the systems to be controlled. The most known one is the Sliding Mode Control identified by its insensitivity to variations in internal and external parameters, stability, simplicity and very low response times [2] [3].The principle of this technique consists in bringing 
the system state trajectory towards the sliding surface and to switch it by means of appropriate switching logic around it to the equilibrium point[4] [5].

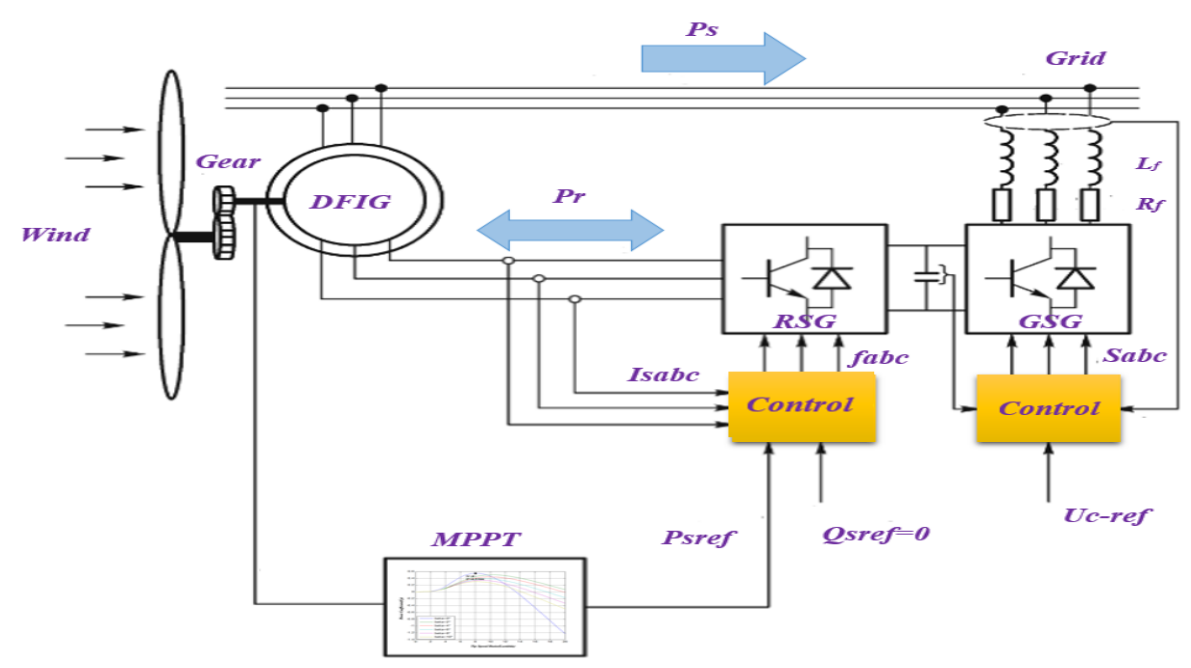

Figure 1. Global wind energy conversion system

In this paper, the modeling of the wind system as well as the MPPT strategy will be presented, in addition to a study of the DFIG model in the Park referential. After that, we will discuss the theoretical part of sliding mode control, followed by its application to the RSC to independently control the active and reactive powers generated by the DFIG, and to the GSC to ensure a DC-BUS voltage and ensure sinusoidal currents in the side of the grid. Finally, we will present and examine the simulation results using MATLAB / SIMULINK so as to make a comparison with the linear control by Flux Oriented Control with the objective of improving the wind system performance.

\section{THE MECHANICAL PART OF THE SYSTEM}

\subsection{Mathematical Model Of The Turbine}

The kinetic power of the wind according to Bernoulli's theorem is given as a function of the area swept by the turbine blades(S), the air density $(\rho)$ and the wind speed $(\mathrm{V})$ by the following Equation [6-9]:

$$
\mathrm{P}_{\mathrm{v}}=\frac{\rho . S \cdot \mathrm{V}^{3}}{2}
$$

The wind turbine can convert a percentage of the kinetic wind power into a mechanical power. The aerodynamic power appearing at the rotor of the turbine is written as follows [9-11]:

$$
P_{\text {aero }}=C_{p}(\lambda, \beta) \cdot \frac{\rho \cdot \pi \cdot R^{2} \cdot V^{3}}{2}
$$

Cp presents the power coefficient as shown in Figure 2, which depends on the characteristic of the wind turbine ( $\lambda$ and $\beta$ ). This later is approximated by the following Equation [10], [8]:

$$
\mathrm{C}_{\mathrm{p}}\left((\lambda, \beta)=\mathrm{C}_{1}\left(\frac{\mathrm{C}_{2}}{\mathrm{~A}}-\mathrm{C}_{3} \cdot \beta-\mathrm{C} 4\right) * \exp \left(-\mathrm{C}_{5} *\left(\frac{1}{(\lambda+0.08 \cdot \beta)}-\frac{0.035}{\beta^{3}+1}\right)\right)+\mathrm{C}_{6} \cdot \lambda\right.
$$

From Figure 2, we can note that the power coefficient $\mathrm{Cp}$ reaches its maximum 0.5506 for a speed ratio $\lambda$ opt $=8$ and $\beta=0^{\circ}$. The speed ratio $\lambda$ presents the relationship between the wind speed and that of the turbine $\Omega$ t.Its expression is given as follows [8-9]:

$$
\lambda=\mathbf{R} \cdot \frac{\Omega_{\mathbf{t}}}{\mathbf{v}}
$$




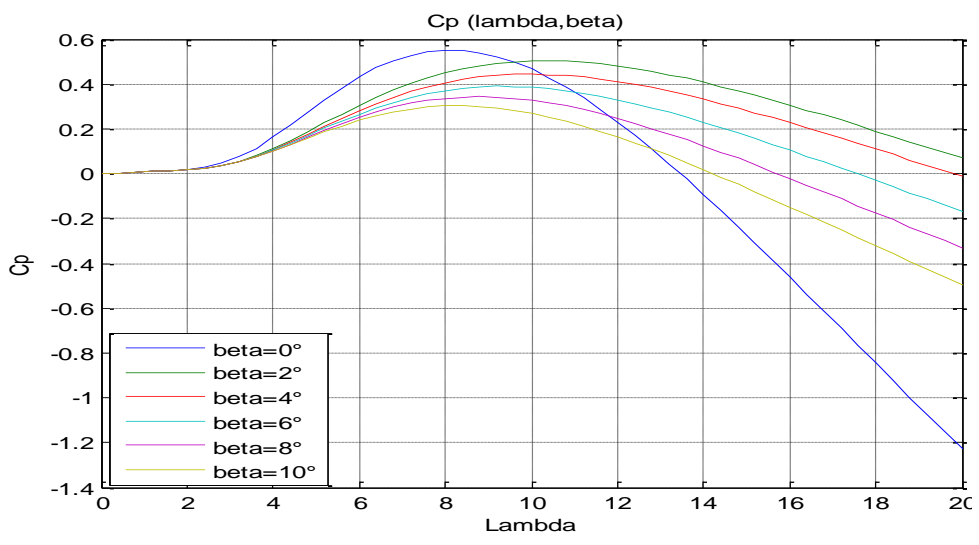

Figure 2. Power coefficient in function of $\lambda$ for diverse values of $\beta$

\subsection{Gerbox}

The gearbox allows to adapt the slow turbine speed to that required by the generator. It is modeled by the following equation system [5-6]:

$$
\left\{\begin{array}{l}
\Omega_{t}=\frac{\Omega_{\text {mec }}}{G} \\
\mathrm{C}_{g}=\frac{\mathrm{C}_{\text {aero }}}{G}
\end{array}\right.
$$

\subsection{Dynamic Equation Of The Shaft}

The fundamental equation of the dynamics makes it possible to define the progress of the mechanical speed $\Omega \operatorname{mec}[8][10]$ :

$$
\mathrm{C}_{m e c}=\mathrm{J} \frac{\mathrm{d} \Omega_{m e c}}{\mathrm{dt}}=\mathrm{C}_{g}-\mathrm{C}_{e m}-f \Omega_{m e c}
$$

With: $C_{m e c}$ : Mechanical torque exerted on the rotor shaft of the wind turbine.Cem: Electromagnetic torque, $f . \Omega_{\text {mec }}$ : The torque of viscous friction.J: The total inertia consists of the turbine inertia Jt and the generator inertia Jg given by:

$$
J=\frac{J_{t}}{G}+J_{g}
$$

\subsection{Maximum Power Point Tracking Strategy}

In order to extract the maximum power from the wind, we need an algorithm acting on the set point variables, to have a good efficiency of the device. For this reason, we applied a technique of Maximum Power Point Tracking Strategy.This technique consists in imposing a torque of reference so as to permit the DFIG to turn at a regulating speed to ensure an optimal operating point of power extraction [3]. That is why the speed ratio $\lambda$ must be kept its optimum value $(\lambda=\lambda$ opt) over a certain range of wind speed, furthermore ,the power coefficient would be maintained at its maximum value $(\mathrm{Cpmax}=\mathrm{Cp})[3,12]$. In this case, the aerodynamic couple will have as an expression:

$$
\mathrm{C}_{\mathrm{aero}}=\mathrm{C}_{\mathrm{p} \_\max }(\lambda, \beta) \cdot \frac{\rho \cdot \pi \cdot \mathrm{R}^{2} \cdot \mathrm{V}^{3}}{2 \cdot \Omega_{\mathrm{t}}}
$$

The reference torque at the output of the multiplier becomes:

$$
\mathrm{C}_{g_{\text {ref }}}=\frac{1}{G} \cdot \mathrm{C}_{\text {aero }}
$$

We know that the fundamental equation of dynamics is given by: 


$$
\mathrm{C}_{m e c}=\mathrm{J} \frac{\mathrm{d} \Omega_{m e c}}{\mathrm{dt}}=\mathrm{C}_{g}-\mathrm{C}_{e m}-\mathrm{C}_{f}
$$

We assumed that the generator rotational speed is fixed during the study period, and we neglected the effect of the viscous torque. The reference electromagnetic torque can be expressed by:

$$
\mathrm{C}_{\text {emref }}=\mathrm{C}_{g}
$$

The estimated wind speed can be written as suggested:

$$
V_{e s t}=R \cdot \frac{\Omega_{t_{-} e s t}}{\lambda_{e s t}}
$$

The expression of the reference electromagnetic torque can be written as indicated:

$$
\mathrm{C}_{\mathrm{emref}}=\frac{\mathrm{C}_{\mathrm{p}_{-} \max }}{\lambda_{\mathrm{opt}}^{3}} \cdot \frac{\rho \cdot \pi \cdot \mathrm{R}^{5}}{2} \cdot \frac{\Omega_{\mathrm{mec}}^{2}}{\mathrm{G}^{3}}
$$

Based on these equations, we can create the following diagram of the mechanical part of the wind system and the MPPT strategy without speed measurement shown in Figure 3 [5]:

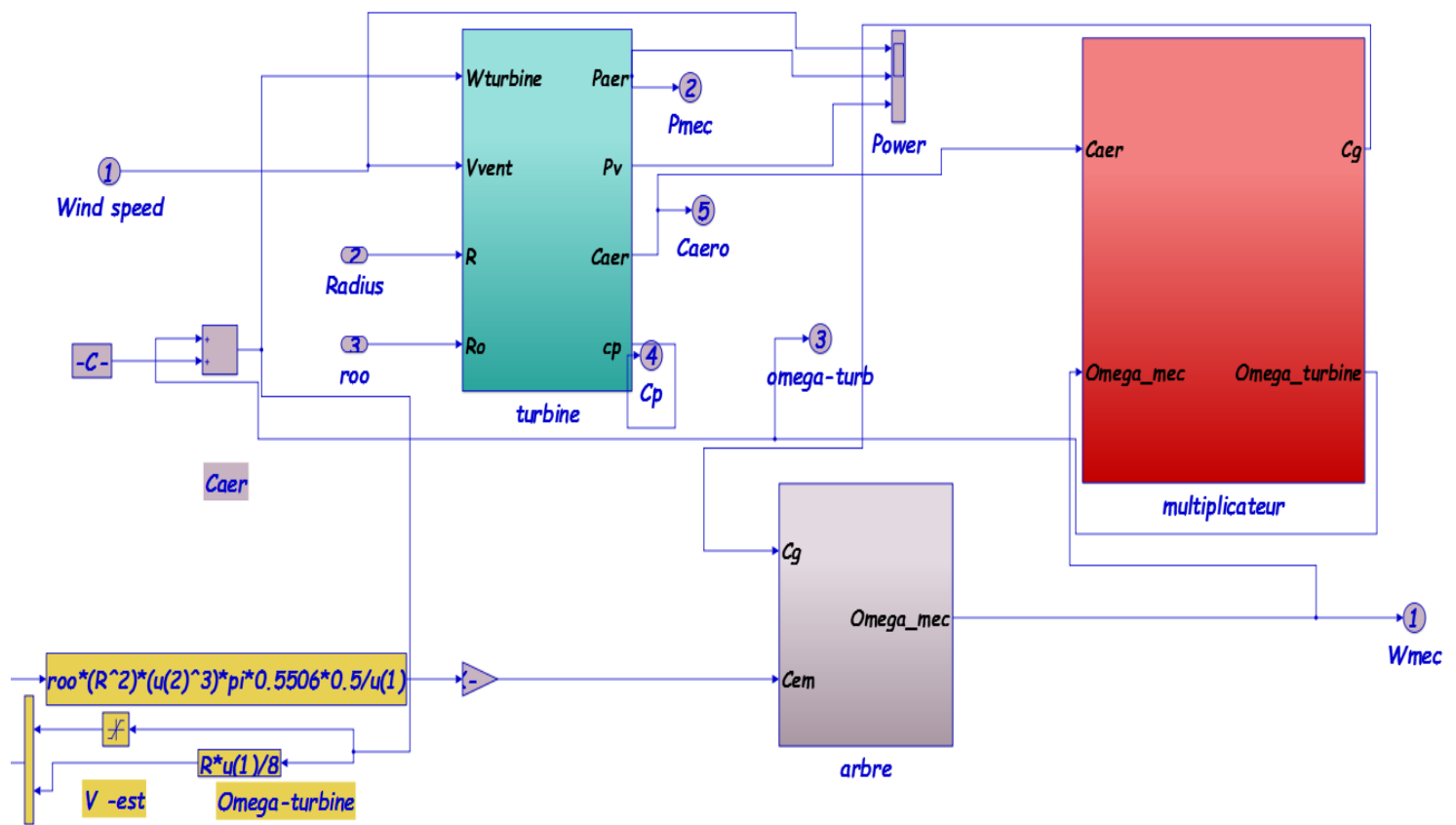

Figure 3. The MPPT strategy without speed measurement

\section{THE ELECTRICAL PART OF THE SYSTEM}

\subsection{The DFIG Mode}

The Doubly Fed Induction Generator DFIG model using Park transformation is presented by the following Equations [6-13][23-24]. Stator and rotor voltages in the reference of Park:

$$
\left\{\begin{array}{l}
\mathrm{V}_{\mathrm{sd}}=\mathbf{R}_{\mathrm{s}} \cdot \mathbf{I}_{\mathrm{sd}}+\frac{\mathrm{d} \phi_{\mathrm{sd}}}{\mathrm{dt}}-\omega_{\mathrm{s}} \cdot \phi_{\mathrm{sq}} \\
\mathrm{V}_{\mathrm{sq}}=\mathbf{R}_{\mathrm{s}} \cdot \mathbf{I}_{\mathrm{sq}}+\frac{\mathrm{d} \phi_{\mathrm{sq}}}{\mathrm{dt}}-\omega_{\mathrm{s}} \cdot \phi_{\mathrm{sd}} \\
\mathrm{V}_{\mathrm{rd}}=\mathbf{R}_{\mathrm{r}} \cdot \mathbf{I}_{\mathrm{rd}}+\frac{\mathrm{d} \phi_{\mathrm{rd}}}{\mathrm{dt}}-\omega_{\mathrm{r}} \cdot \phi_{\mathrm{rq}} \\
\mathrm{V}_{\mathrm{rq}}=\mathbf{R}_{\mathrm{r}} \cdot \mathbf{I}_{\mathrm{rq}}+\frac{\mathrm{d} \phi_{\mathrm{rq}}}{\mathrm{dt}}+\omega_{\mathrm{r}} \cdot \phi_{\mathrm{rd}}
\end{array}\right.
$$


Stator and rotor Flux in the reference of Park:

$$
\left\{\begin{array}{l}
\Phi_{s d}=L_{s} . I_{s d}+M . I_{r d} \\
\Phi_{s q}=L_{s} \cdot I_{s q}+M . I_{r q} \\
\Phi_{r d}=L_{r} . I_{r d}+M . I_{s d} \\
\Phi_{r q}=L_{r} \cdot I_{r q}+M . I_{s q}
\end{array}\right.
$$

Electromagnetic Torque:

$$
\mathrm{C}_{\mathrm{em}}=\mathrm{p} \cdot\left(\Phi_{\mathrm{sd}} \cdot \mathrm{I}_{\mathrm{sq}}-\Phi_{\mathrm{sq}} \cdot \mathrm{I}_{\mathrm{sd}}\right)
$$

Active and reactive DFIG powers:

$$
\left\{\begin{array}{l}
\mathbf{P}_{\mathrm{s}}=\mathrm{V}_{\mathrm{sd}} \cdot \mathrm{I}_{\mathrm{sd}}+\mathrm{V}_{\mathrm{sq}} \cdot \mathbf{I}_{\mathrm{sq}} \\
\mathbf{Q}_{\mathrm{s}}=\mathrm{V}_{\mathrm{sq}} \cdot \mathrm{I}_{\mathrm{sd}}-\mathrm{V}_{\mathrm{sd}} \cdot \mathbf{I}_{\mathrm{sq}}
\end{array}\right.
$$

\subsection{Filter (R,L) Model}

The GSC Converter is connected to the DC-BUS and the Grid via a filter (Rf, Lf). It has two roles: sustaining the DC- BUS voltage constance regarding the amplitude and the rotor power direction and maintaining a unit power factor at the link point to the grid [14].The filter model in the referential $(d, q)$ is given by Equation 18:

$$
\left\{\begin{array}{l}
v_{d f}=-R_{f} I_{d f}-L_{f} \frac{d I_{d f}}{d t}+\omega_{s} L_{f} I_{q f}+v_{s d} \\
v_{q f}=-R_{f} I_{q f}-L_{f} \frac{d I_{q f}}{d t}-\omega_{s} L_{f} I_{d f}+v_{s q} \\
P_{f}=v_{d f} I_{d f}+v_{q f} I_{q f} \\
Q_{f}=v_{q f} I_{d f}-v_{d f} I_{q f}
\end{array}\right.
$$

\section{FLUX ORIENTED CONTROL TECHNIQUE}

\subsection{Flux Oriented Control Principle}

The principle of Flux Oriented Control FOC consists in orienting the flux along one of the axes in order to make the functioning of the induction machine identical to that of the DC machine separately excited[5] [6] .In this case we have chosen to place the stator flux on the axis"d" as shown in Figure 4.

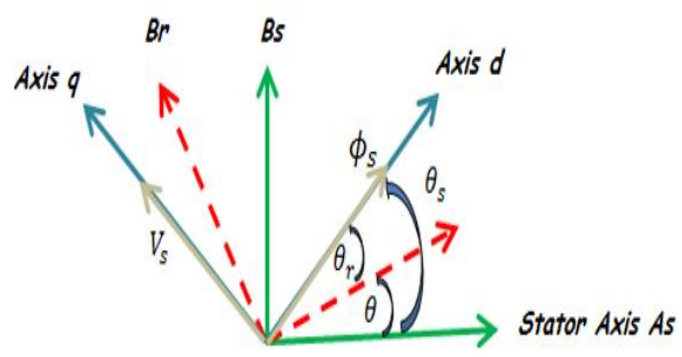

Figure 4. Stator flux orientation

As a result of this orientation, the quadrature part of the stator flux is null and the direct component is equal to the total stator flux. So, we get the following equation:

$$
\left\{\begin{array}{l}
v_{s q}=v_{s} \\
v_{s d}=\mathrm{O}
\end{array}\right.
$$




\subsection{Application of the Flux Oriented Control FOC to the RSC}

According to the Flux Oriented Control principle, the previous equations become as follows:

$$
\left\{\begin{array}{l}
\mathrm{V}_{\mathrm{sd}}=\mathrm{O}, \mathrm{V}_{\mathrm{sq}}=\mathrm{V}_{\mathrm{s}}=\omega_{\mathrm{s}} \cdot \phi_{\mathrm{s}} \\
\mathrm{P}_{\mathrm{s}}=-\mathrm{V}_{\mathrm{s}} \cdot \frac{\mathrm{M}}{\mathrm{L}_{\mathrm{s}}} \cdot \mathrm{I}_{\mathrm{rq}} \\
\mathrm{Q}_{\mathrm{s}}=\frac{\mathrm{V}_{\mathrm{s}}^{2}}{\omega_{\mathrm{s}} \cdot \mathrm{L}_{\mathrm{s}}}-\mathrm{V}_{\mathrm{s}} \cdot \frac{\mathrm{M}}{\mathrm{L}_{\mathrm{s}}} \cdot \mathrm{I}_{\mathrm{rd}} \\
V_{r q}=\left(R_{r}+S \cdot\left(L_{r}-\frac{M^{2}}{L_{s}}\right) \cdot I_{r q}+\omega_{s} \cdot g \cdot\left(L_{r}-\frac{M^{2}}{L_{s}}\right) \cdot I_{r d}+\frac{g \cdot M \cdot V_{s}}{L_{s}}\right. \\
V_{r d}=\left(R_{r}+S \cdot\left(L_{r}-\frac{M^{2}}{L_{s}}\right) \cdot I_{r d}-\omega_{s} \cdot g \cdot\left(L_{r}-\frac{M^{2}}{L_{s}}\right) \cdot I_{r q}\right.
\end{array}\right.
$$

\subsection{Application of the Flux Oriented Control FOC to the GSC}

In order to obtain a robust wind turbine system with variable speed, we need to control the GSC, so that the DC-BUS voltage will kept a constant value to ensure a good DC-BUS voltage regulation and a unit power side of the grid.By using Flux Oriented technique FOC, the previous equations are as follows:

$$
\left\{\begin{array}{c}
v_{d f}=-R_{f} I_{d f}-L_{f} \frac{d I_{d f}}{d t}+\omega_{s} L_{f} I_{q f} \\
v_{q f}=-R_{f} I_{q f}-L_{f} \frac{d I_{q f}}{d t}-\omega_{s} L_{f} I_{d f}+v_{s} \\
P_{f}=v_{s} I_{q f} \\
Q_{f}=-v_{s} I_{d f}
\end{array}\right.
$$

Then, we can set up a filter current controller (Rf, Lf) with a decoupling between the magnitudes which allows their independent control. The relation between the Filter Currents and the Filter Voltages is given by the following equation:

$$
\left\{\begin{array}{c}
v_{d f}=-\left(R_{f}+S \cdot L_{f}\right) \cdot I_{d f}+\omega_{s} L_{f} I_{q f} \\
v_{q f}=-\left(R_{f}+S \cdot L_{f}\right) \cdot I_{q f}-\omega_{s} L_{f} I_{d f}+v_{s}
\end{array}\right.
$$

\section{SLIDING MODE CONTROL SMC}

\subsection{Sliding Mode Control Principle}

The variable structure system (VSS), is a system whose structure changes during its operation. It is characterized by the choice of a structure and a switching logic. This latter allows the system to switch from one structure to another at any time by the choice of a function, which separates the state space into two parts as shown in Figure 5, and an appropriate switching logic. The Sliding mode technique is a special case of (VSS). It consists of forcing the system state trajectory to attain a hyper surface in finite time and then stay there. This latter presents a relation between the system state variables which defines a differential equation, and consequently, determines the system dynamics if it remains on the hyper surface. The evolution of a system subject to a control law no longer depends on the system or the external disturbances, but on the properties of the hyper surface. The system will therefore be robust not only to uncertainties (specific to the system) and disturbances (external to the system) but will be totally insensitive because they are completely rejected by the control [15].

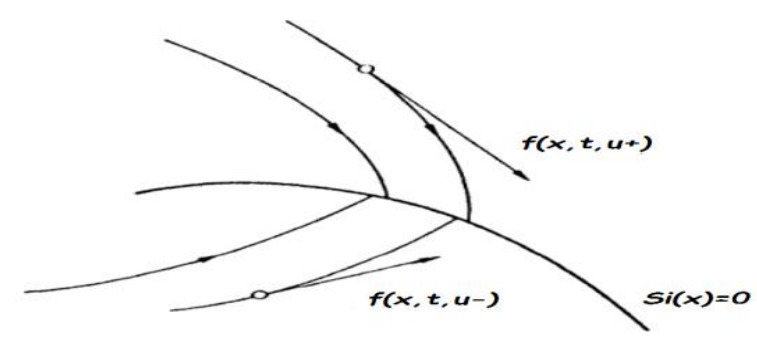

Figure 5. Sliding mode technique principle 
The plan of the sliding mode control algorithm is mainly carried out in three steps defined by [5]:

\section{Sliding surface}

The sliding surface proposed by SLOTINE is given by $[16,17]$ :

$$
\mathrm{S}(\mathrm{x}, \mathrm{t})=\left(\frac{\partial}{\partial \mathrm{t}}+\lambda\right)^{(\mathrm{n}-1)} \mathrm{e}(\mathrm{x})
$$

With: e (x): deviation of the variable to be adjusted $\mathrm{e}(\mathrm{x})=\mathrm{xref}-\mathrm{x}, \lambda$ : positive constant.n: presents the number of times it derives the output to make the command appear .

\section{Convergence condition}

To ensure the sliding mode control stability, LYAPUNOV proposes a positive function V (x) which guarantees the nonlinear system stability and the attraction of the state variable to its reference value. This latter is defined as follows $[3,5]$ :

$$
\mathrm{V}(\mathrm{x})=\frac{1}{2} \cdot \mathrm{S}(\mathrm{x})^{2}
$$

The function $\mathrm{V}(\mathrm{x})$ derivation must be negative, so that the variable $\mathrm{S}(\mathrm{x}, \mathrm{t})$ can tend towards zero, as shown in the following equation :

\section{Control Law}

$$
\mathrm{V}(\mathrm{x})=\mathrm{S}(\mathrm{x}) \mathrm{S}(\mathrm{x})<\mathrm{O}
$$

The command $(\mathrm{u})$ is a variable structure command given by [19]:

$$
\mathrm{u}=\left\{\begin{array}{lll}
\mathrm{u}^{+}(\mathrm{x}) & \text { if } & s(\mathrm{x}, \mathrm{t})>0 \\
\mathrm{u}^{-}(\mathrm{x}) & \text { if } & s(\mathrm{x}, \mathrm{t})<0
\end{array}\right.
$$

The control $(\mathrm{u})$ of discontinuous nature, will oblige the system trajectories to reach the sliding surface and to remain on that surface in vicinity of this latter, regardless of the disturbances. According to the equation system (26), we can note that the command (u) is not defined for $\mathrm{S}=0$.For this reason, FILLIPOV [19] and UTKIN [20] propose a method called the equivalent command [5,18], shown in the following Figure 6.

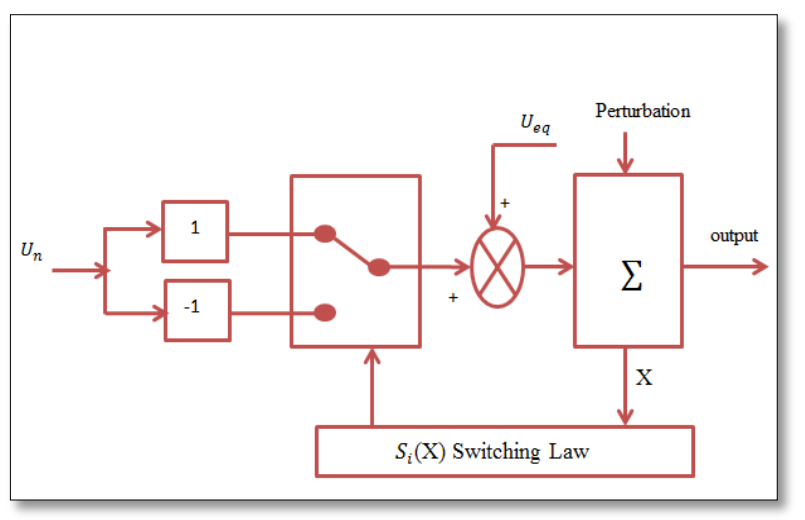

Figure 6. the equivalent command

From Figure 6, we can see that the equivalent command is expressed by;

$$
\mathbf{u}=\mathbf{u}_{\mathbf{e q}}+\mathbf{u}_{\mathbf{n}}
$$

Ueq: presents the equivalent part of the control used to keep on the sliding surface, the variable which must be controlled: 


$$
S(x)=S(x)=0
$$

$\mathrm{u}_{\mathrm{n}}$ : The stabilizing control allows us to ensure a convergence as well as the robustness regarding the disturbances.

$$
\mathrm{U}_{\mathrm{n}}=\mathrm{K} \cdot \operatorname{sign}(\mathrm{S}(\mathrm{x}))
$$

The main disadvantage of this control type is the phenomenon known by « CHATTERING» $[3,5]$ which appears in steady state as a high frequency oscillation around the equilibrium point, because of the very discontinuous nature of the sign function.To solve this problem, several techniques have been applied, among them we find the one proposed by J.SLOTINE which consists of replacing the "SIGN" function by the "SAT" function given by :

$$
\operatorname{Sat}(S)= \begin{cases}\operatorname{Sat}(S)=1 & \text { if } S>\varepsilon \\ \operatorname{Sat}(S)=-1 & \text { if } S<\varepsilon \\ \operatorname{Sat}(S)=\frac{S}{\varepsilon} & \text { if }|S|<\varepsilon\end{cases}
$$

\subsection{RSC Control Using Sliding Mode Control}

Considering the sliding surface proposed by SLOTINE and taking $n=1$, we obtain:

$$
\left\{\begin{array}{c}
S\left(P_{s}\right)=e_{1}=P_{\text {sref }}-P_{s} \\
S\left(Q_{s}\right)=e_{2}=Q_{s r e f}-Q_{S}
\end{array}\right.
$$

With: Qsref and Psref are the reactive and active powers references.The derivative of sliding surface is given by :

$$
\left\{\begin{array}{l}
\&=\mathbb{L}_{s r e f}^{\&}+\frac{V_{s} \cdot M}{L_{s}} \cdot\left(\frac{V_{r q e q}+V_{r q n}}{L_{r} \cdot \sigma}-\frac{R_{r}}{L_{r} \cdot \sigma} \cdot I_{r q}-\omega_{r} \cdot I_{r d}-\omega_{r} \cdot V_{s} \cdot \frac{M}{L_{r} \cdot L_{s} \cdot \omega_{s} \cdot \sigma}\right) \\
\&=\bigotimes_{s r e f}^{\&}+V_{s} \cdot \frac{M}{L_{s}} \cdot\left(\frac{V_{r d e q}+V_{r d n}}{L_{r} \cdot \sigma}-\frac{R_{r}}{L_{r} \cdot \sigma} \cdot I_{r d}+\omega_{r} \cdot I_{r q}\right)
\end{array}\right.
$$

During the sliding and permanent mode, we have:

$$
\left.e_{(1,2)}=0, \& 4,2\right)=0, V_{r d n}=V_{r q n}=0
$$

The expression of the equivalent command becomes:

$$
\left\{\begin{array}{l}
V_{r d e q}=-\frac{L_{r} \cdot L_{S} \cdot \sigma}{M \cdot V_{s}} \cdot \bigotimes_{s r e f}^{\&}+R_{r} \cdot I_{r d}-\omega_{r} \cdot L_{r} \cdot \sigma \cdot I_{r q} \\
V_{r q e q}=-L_{r} \cdot L_{s} \cdot \frac{\sigma}{V_{s} \cdot M} \cdot H_{s r e f}^{\&}+R_{r} I_{r q}+L_{r} \cdot \omega_{r} \cdot \sigma \cdot I_{r d}+\omega_{r} \cdot M \cdot \frac{V_{S}}{L_{s} \cdot \omega_{s}}
\end{array}\right.
$$

Therefore, the stabilizing control is given by the following equation:

$$
\left\{\begin{array}{l}
V_{r d n}=K_{d} \operatorname{sat}\left(e_{2}\right) \\
V_{r q n}=K_{q} \operatorname{sat}\left(e_{1}\right)
\end{array}\right.
$$

\subsection{GSC Control Using Sliding Mode Control}

We consider the SLOTINE's sliding mode surface.For $n=1$, we obtain :

$$
\left\{\begin{array}{l}
S\left(P_{f}\right)=e_{3}=P_{\text {fref }}-P_{f} \\
S\left(Q_{f}\right)=e_{4}=Q_{\text {fref }}-Q_{f}
\end{array}\right.
$$


Where: Qfref and Pfref are the reactive and active powers references. The derivative of the sliding surface is given by:

$$
\left\{\begin{array}{c}
\&=I_{\text {ref }}+\frac{V_{s} \cdot R_{f}}{L_{f}} \cdot I_{q f}+\frac{V_{s}\left(V_{q f e q+} V_{q f n}\right)}{L_{f}}+w_{s} \cdot V_{s} \cdot I_{d f}-\frac{V_{s}^{2}}{L_{f}} \\
\&=Q_{f r e f}-\frac{V_{s} \cdot R_{f}}{L_{f}} \cdot I_{d f}-\frac{V_{s}\left(V_{d f e q+} V_{d f n}\right)}{L_{f}}+w_{s} \cdot V_{s} \cdot I_{q f}
\end{array}\right.
$$

In the sliding and permanent mode, we obtain the expression of the equivalent command supplied as follows:

$$
\left\{\begin{array}{c}
V_{d f e q}=\frac{L_{f}}{V_{s}} \cdot \mathcal{Q}_{f r e f}-R_{f} \cdot I_{d f}+L_{f} \cdot w_{s} \cdot I_{q f} \\
V_{q f e q}=-\frac{L_{f}}{V_{s}} \cdot I_{f r e f}-R_{f} \cdot I_{q f}-L_{f} \cdot w_{s} \cdot I_{d f}+V_{s}
\end{array}\right.
$$

The stabilizing control is expressed by :

$$
\left\{\begin{array}{l}
V_{d f n}=K_{d f n} \operatorname{sat}\left(e_{4}\right) \\
V_{q f n}=K_{q f n} \operatorname{sat}\left(e_{3}\right)
\end{array}\right.
$$

\section{DC-BUS VOLTAGE CONTROL LOOP}

The DC-BUS equation can be expressed as indicated [21]:

$$
\left\{\begin{array}{l}
W_{c}=\int P_{c} \cdot d t=\frac{1}{2} \cdot C \cdot U_{d c}^{2} \\
\frac{d U_{d c}^{2}}{d t}=\frac{2}{C} \cdot\left(P_{f}-P_{r}\right)
\end{array}\right.
$$

With: Wdc: the DC- Bus energy, and Pc DC- Bus power. By neglecting all the losses exchanged between the electrical grid and the rotor of the DFIG, the powers involved on the DC-BUS can be written as follows:

$$
\left\{\begin{array}{c}
P_{f}=P_{c}+P_{r} \\
P_{c}=U_{d c} I_{c}
\end{array}\right.
$$
BUS voltage.

We can control the power Pc in the capacitor by regulating the power Pf, and thus to adjust the DC-

\section{RESULTS AND DISCUSSION}

In order to gauge the performance of the wind system based on the Doubly Fed Induction Generator, we tested the operation of the wind system by two types of control: the linear control by Flux Oriented Control Technique and the nonlinear control by sliding mode technique to control the powers generated by the DFIG and also to control the DC-BUS Voltage. To carry out this work, two tests were performed:

a. Test 1: Tracking and regulation tests for SMC and PI.

b. Test 2: The tests of robustness regarding the variation parameters.

The results obtained for the various simulation tests, are respectively exposed on the Figure:

a. Figure 11 presents the tracking and regulation tests for SMC and PI.

b. Figure 12 presents the tests of robustness regarding the variations parameters.

By applying a wind profile given by (Figure.a), we can observed the performance of the turbine shown in Figure 10. 


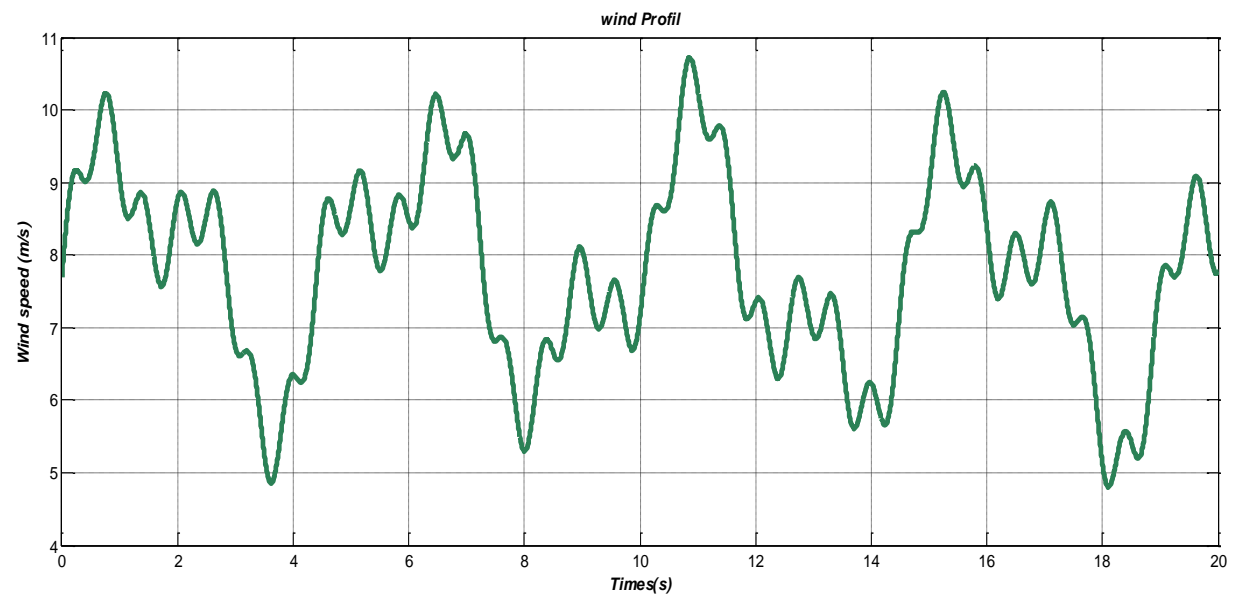

(a)

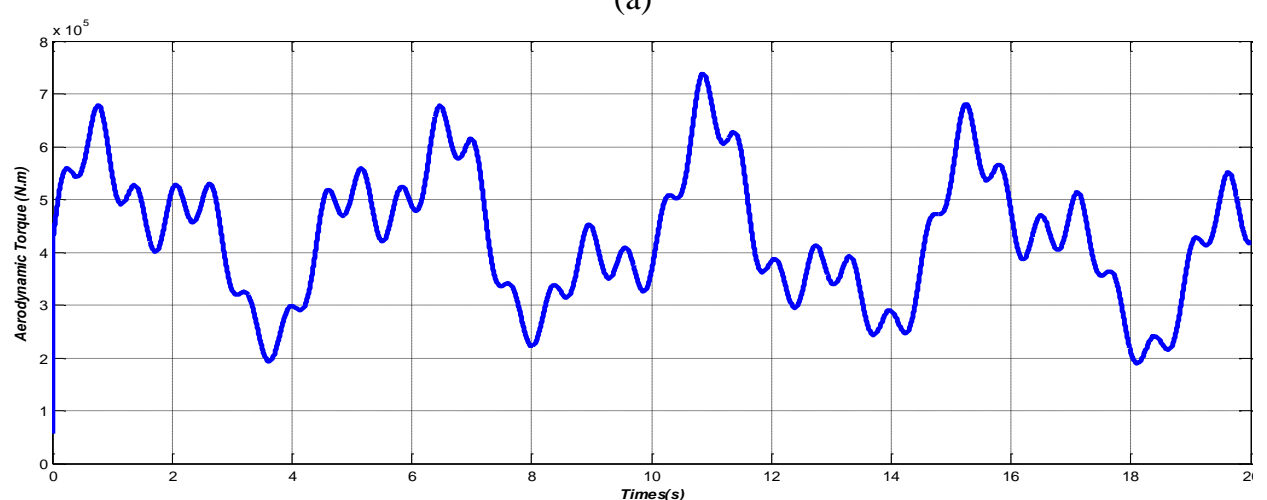

(b)

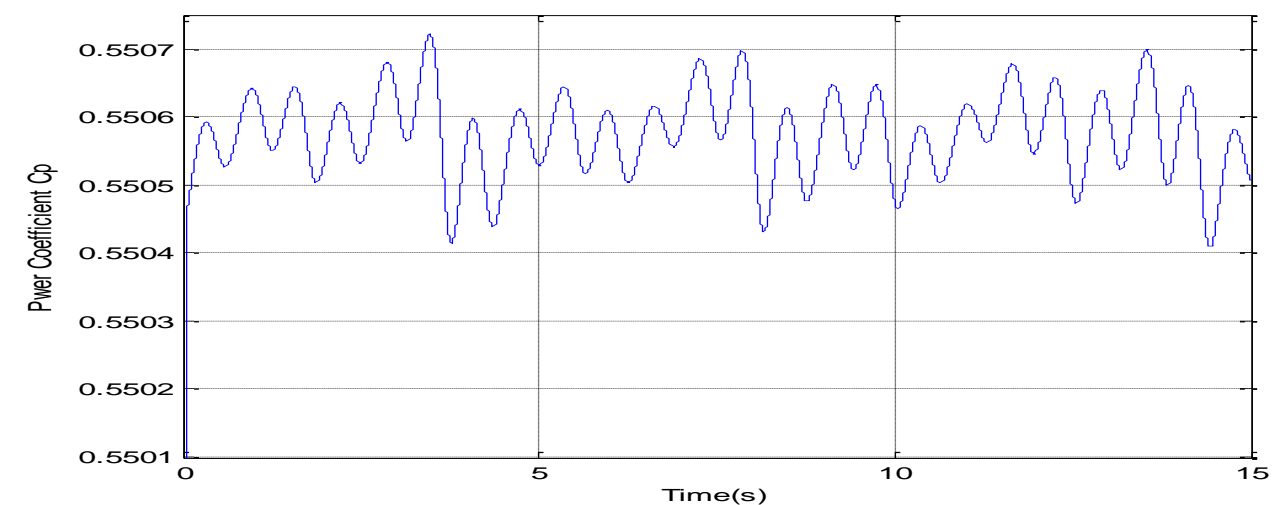

(c)

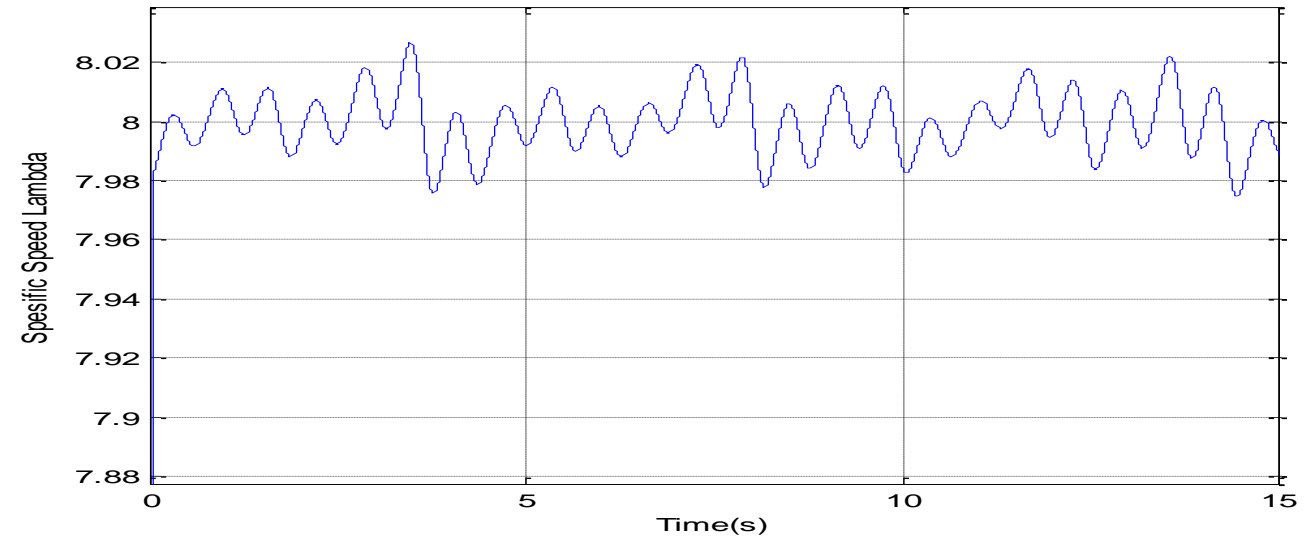

(d)

Figure 10. the performances of wind turbine according to the MPPT strategy 
From these Figures, we can see that the aerodynamic power according to the MPPT (b) has the same form as that of the wind profile. We can also see that the power coefficient (c) and the specific speed lambda (d) reach their maximum values which ensure that the wind system can provide an optimal power from the wind.

\subsection{Tracking Tests}

In this case, we consider the aerodynamic power according to the MPPT strategy as a reference for the stator active power of the DFIG and zero as a reference of the stator reactive power to guarantee a unit power factor on the stator side to optimize the quality of the energy reverted on the grid. By these Figures, we demonstrate the active and reactive power variations.

From Figure 11 (Figure(a) and Figure (b)), the references power are well followed for both controllers (PI and SMC). However, we can see the advantage of the Sliding Mode SM approach presented in the short response time $(\mathrm{TPI}=0.045 \mathrm{~s}, \mathrm{TSMC}=0.003 \mathrm{~s})$ and the perfect tracking of their reference compared to the PI controller.The stator active power (Figure .a) is negative Ps $<0$ means that the grid receives the energy produced from the DFIG.The stator currents Is-abc (Figure.c and Figure.d), have a sinusoidal shape for both controllers but with an improvement in quality for the SMC.From Figure.e, we can observe that the DC-BUS voltage follows perfectly its reference for both controllers but with a very short response time, and less undulations for the Sliding Mode Controller.

\subsection{Robustness Tests}

The previous test was done considering the fixed machine parameters, but these parameters can be influenced by several physical phenomena such as the temperature which allows the increase of the resistance values, the saturation of the inductors ... etc.In addition, the identification of these parameters is expressed in infidelities owing to measuring devices and the adopted methodology. Therefore, it is interesting to compare the performance of both systems regarding this phenomenon. To test the performance of each controller against model uncertainties affecting system stability, we replace the parameters of the system used in the DFIG by the following equation: $\left\{R_{(s, r)}=2 R_{n}, L_{(s, r)}=1.2 L_{n}\right.$

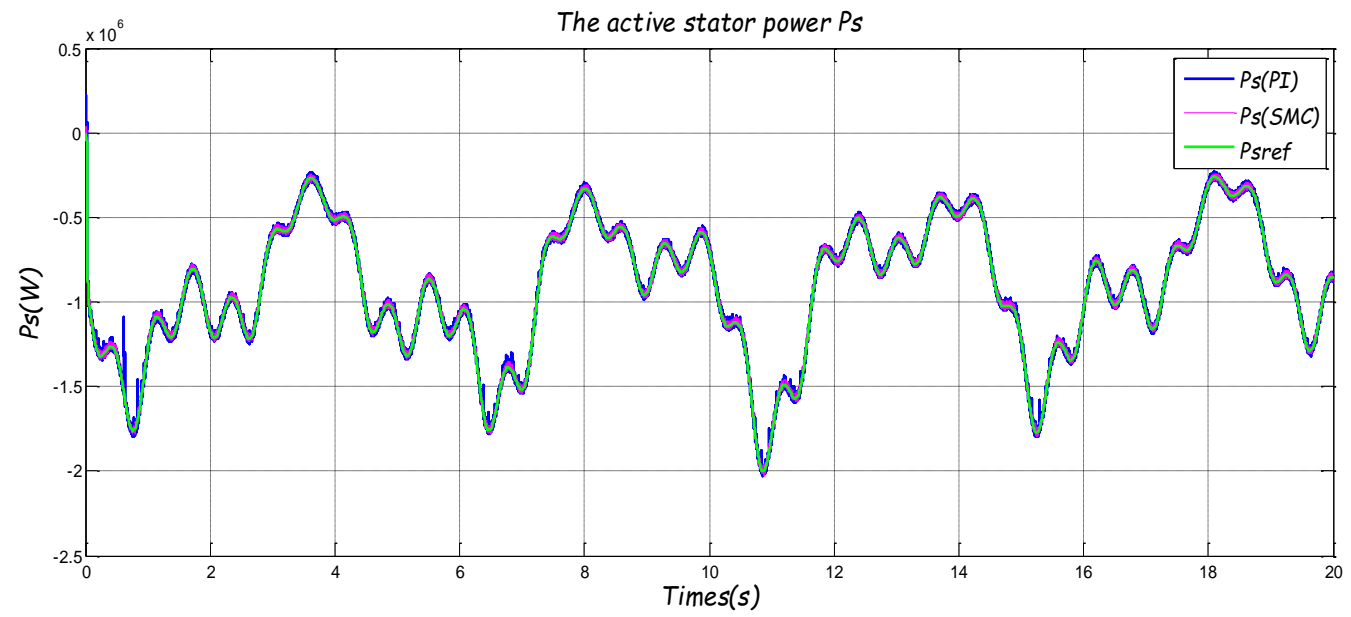

(a) 


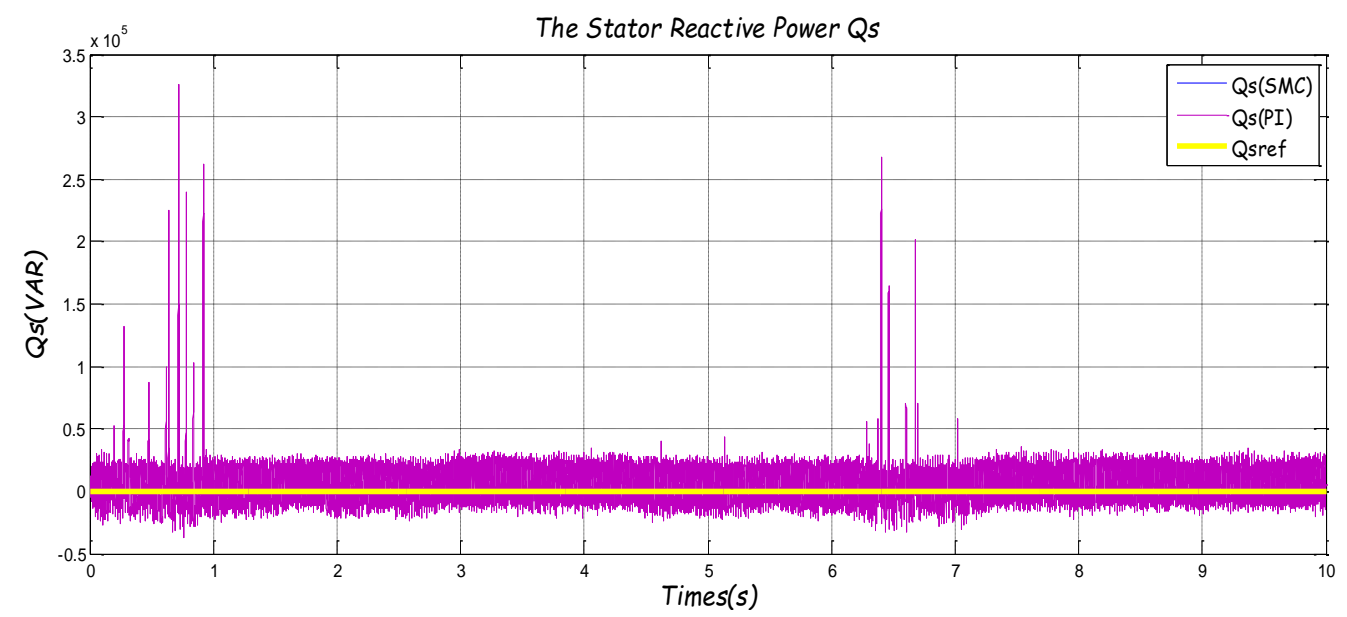

The stator Currents (is abc) for PI

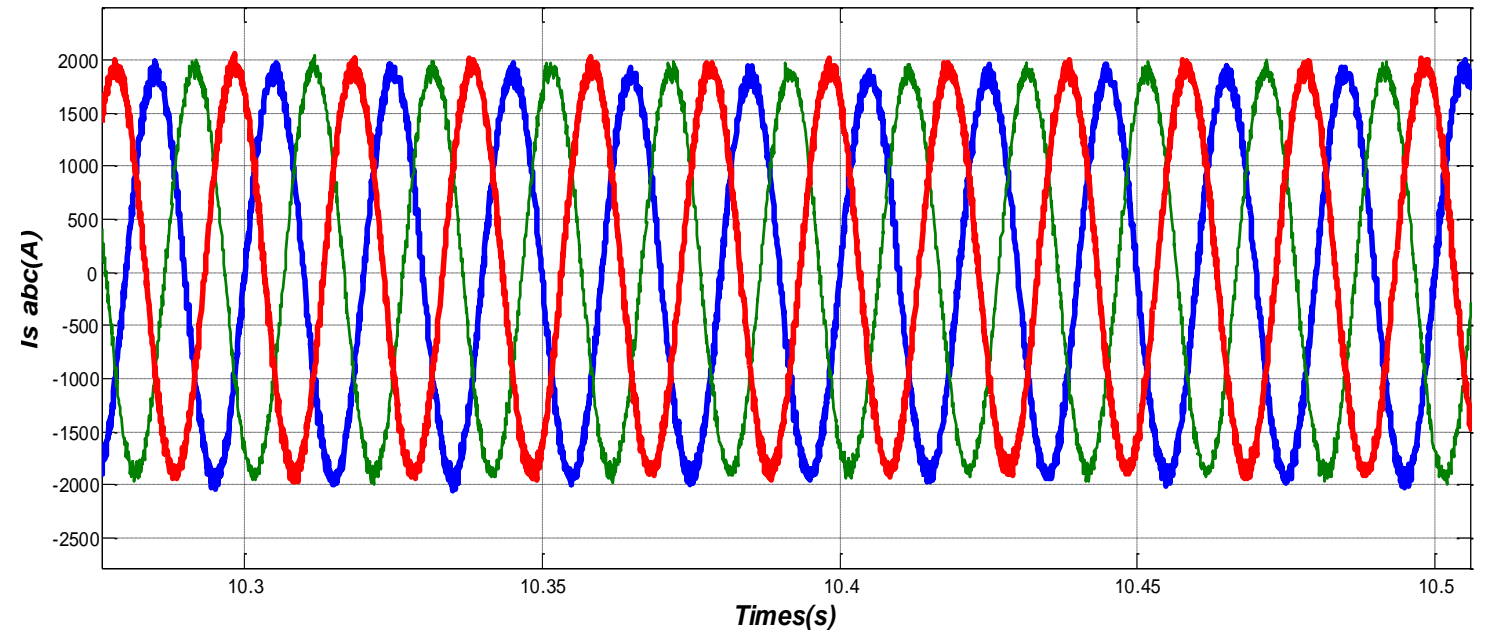

(c)

Stator currents (is abc) for SMC

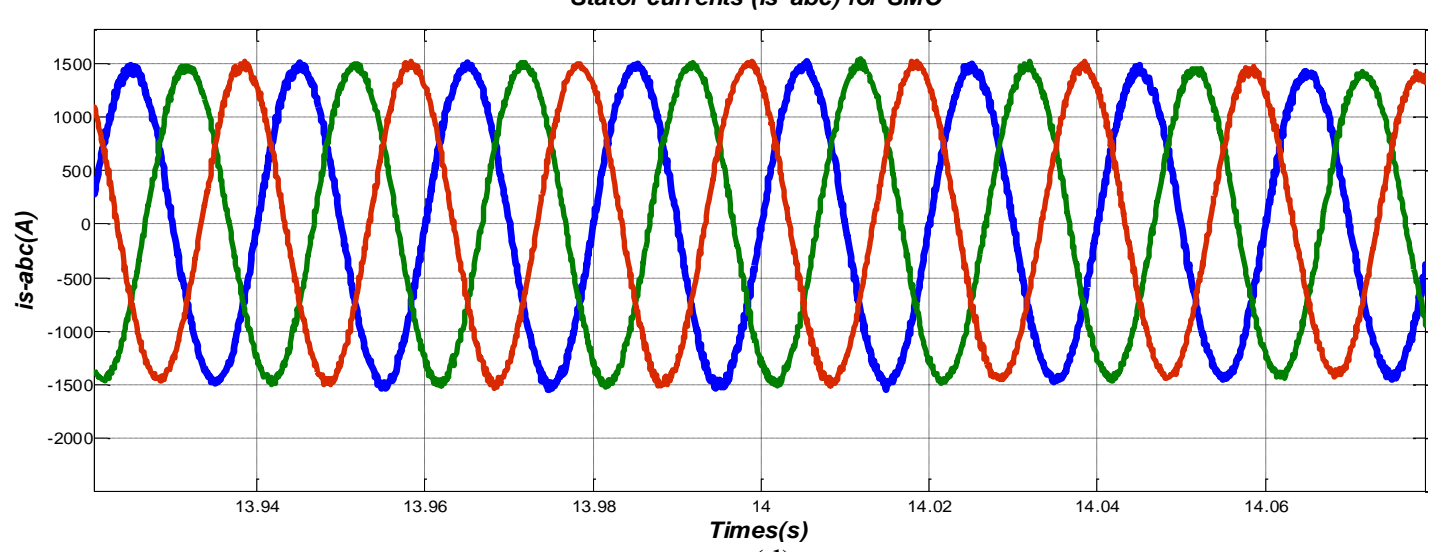

(d) 


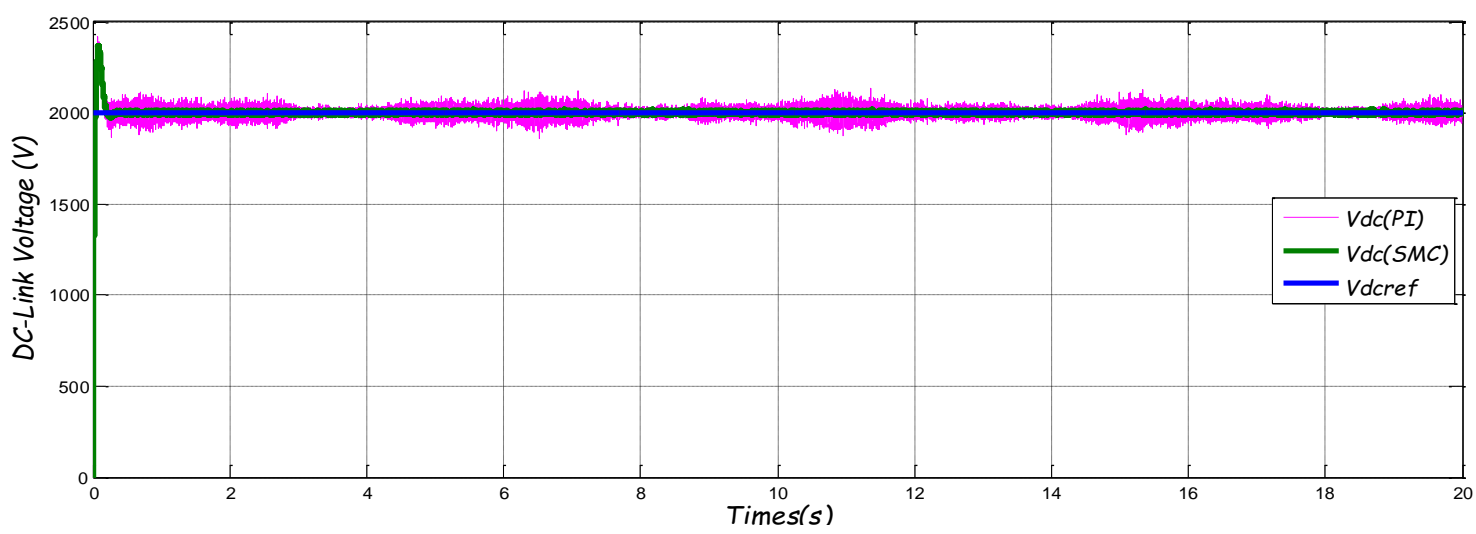

(e)

Figure 11. Tracking test for SMC and PI

From Figure.12, we can note that the SMC controller is not influenced by the parametric variations compared to the PI controller where we see a slight variation and a response time that has been significantly increased. Which confirms the Sliding Mode Technique robustness regarding the system parametric variation.

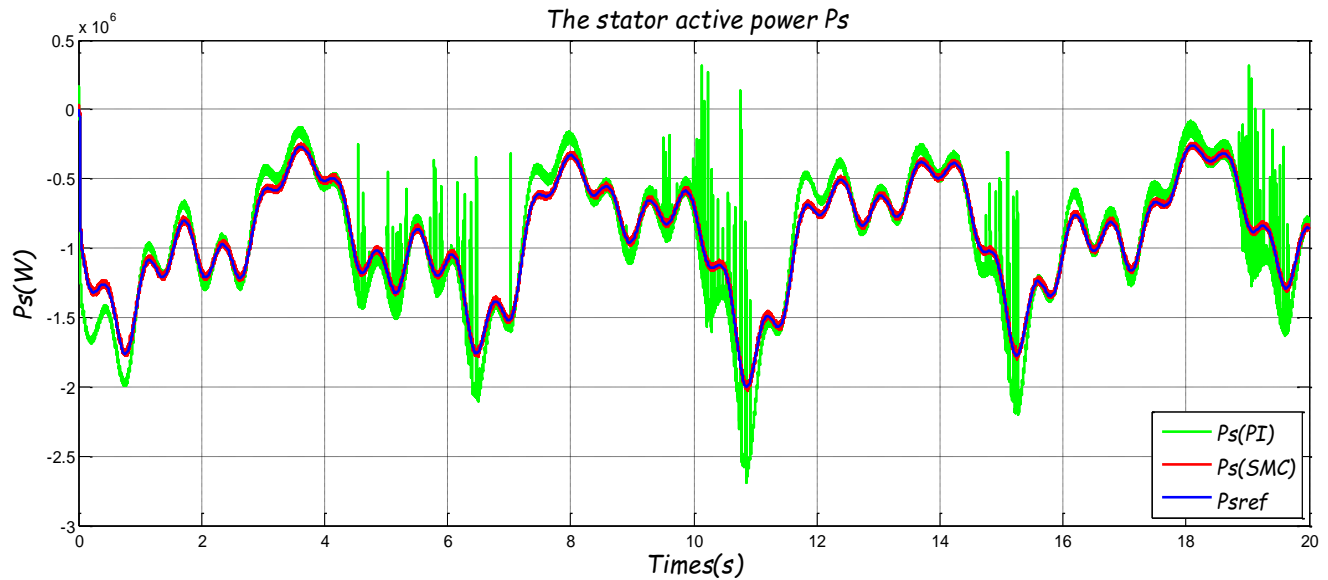

(a)

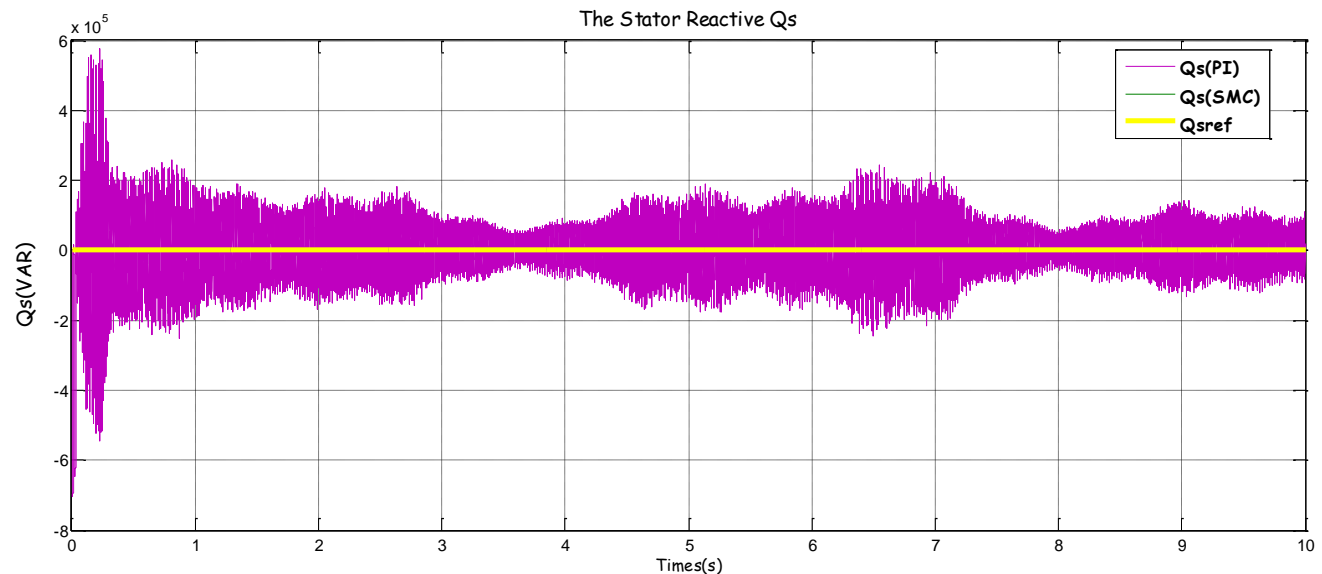

(b) 


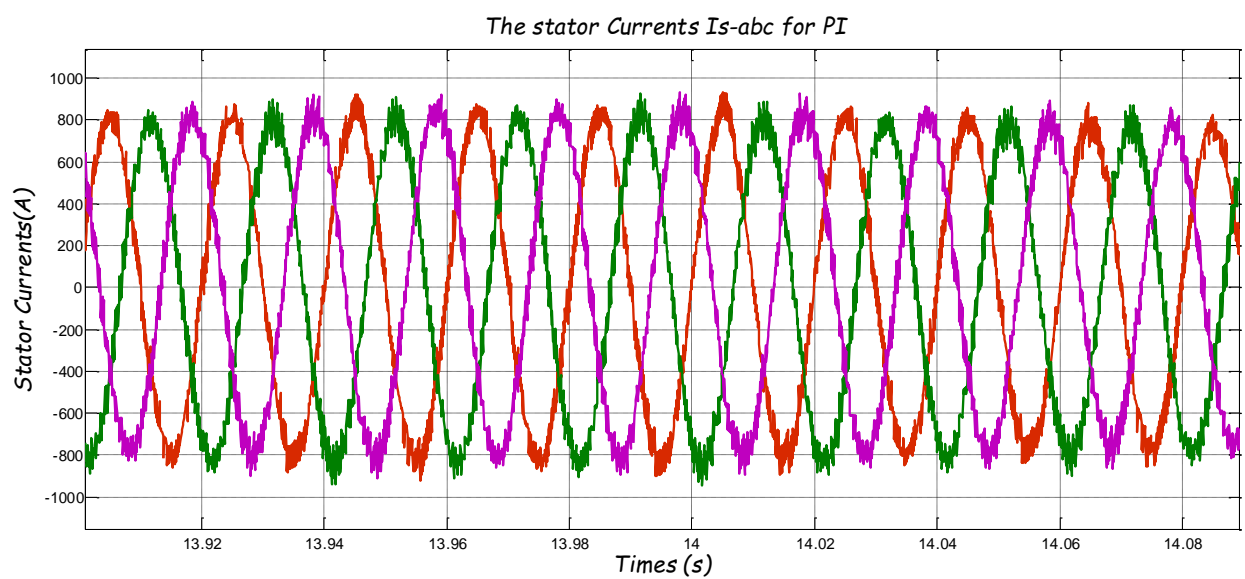

(c)

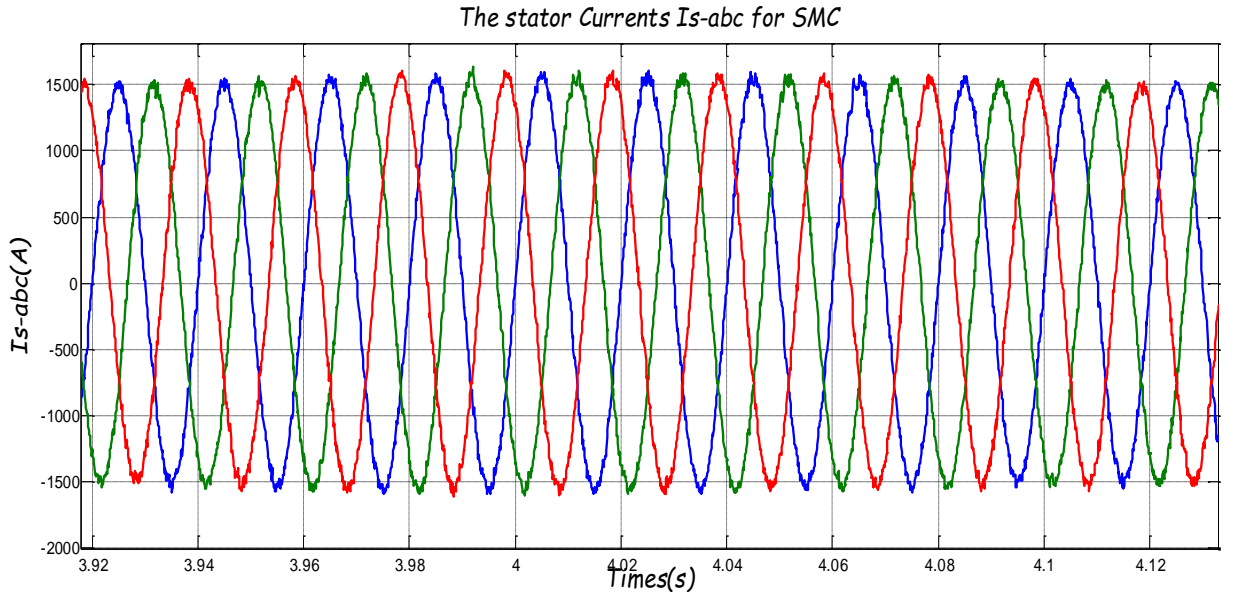

(d)

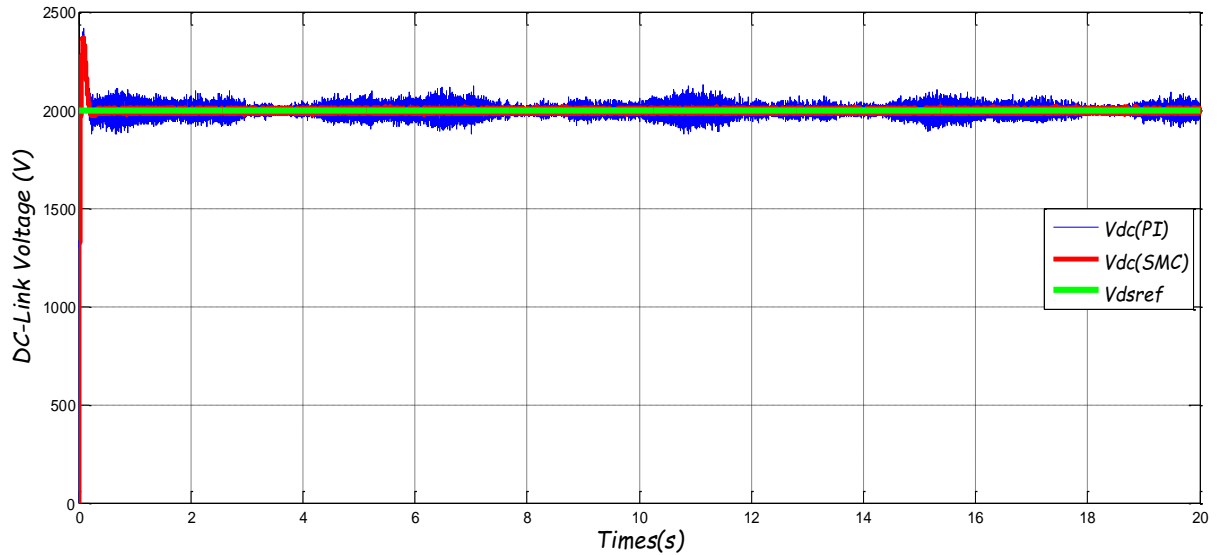

(e)

Figure 12. Robustness tests for SMC and PI

\section{CONCLUSION}

This work presents a comparative analysis between the Sliding Mode Technique and the Flux Oriented Control using PI controller applied to the wind system based on a Doubly Fed Induction Generator DFIG in order to control the Back-to-back converters (RSC and GSC) with the objective of extracting and transmitting the maximum of the wind power to the grid.Firstly, we modeled the turbine, the DFIG as well as the RSC and GSC converters in order to apply both control techniques PI and SMC.Secondly, we used the MPPT control technique to provide the active power reference for our control block, while the reactive power is kept equal to zero, in order to keep a unit power factor.The simulation results present the performances of 
the proposed algorithms, in terms of monitoring and robustness against parametric variations. We performed two simulations for each controller. We found that the SMC provides more powerful and meaningful results compared to the PI controller and therefore this technique presents a good contender for controlling DFIG integrated in a wind power system.

\section{REFERENCES}

[1] X. S. Li, et al., "Analysis and Simplification of Three-Dimensional Space Vector PWM for Three-Phase Four-Leg Inverters," IEEE Transactions on Industrial Electronics, vol. 58, pp. 450-464, Feb 2011.

[2] Canudas,D., Commande des moteurs asynchrone, modélisation contrôle vectoriel et DTC ,HERMES/LAVOISIER ,Paris, (2000).

[3] Gille, J. C., Decaulne, P., \& Pélegrin, M. “Systèmes asservis non linéaires”, 5,Dunod. (1975).

[4] LOUCIF, M., "Synthèse de lois de commande non-linéaires pour le contrôle d'une machine asynchrone à double alimentation dédiée à un système aérogénérateur",Phd.Thesis, Université Aboubakr Belkaïd, Faculté de TECHNOLOGIE-Tlemcen-, (2016).

[5] Buhler,H., "Réglage par mode de glissement. ”, Première Edition. éd., Lausanne, Suisse: Presses Polytechniques et Universitaires Romandes.( 1986),

[6] BEKAKRA,Y., "Contribution à l'Etude et à la Commande Robuste d'un Aérogénérateur Asynchrone à Double Alimentation.”, Phd.Thesis, Université Mohamed Khider, Biskra., (2014).

[7] Ihedrane ,Y., EL Bekkali, C. , Bossoufi, B. , "Power Control of DFIG-generators for Wind Turbines Variablespeed. ”, International Journal of Power Electronics and Drive Systems (IJPEDS) ,8(1):444-453, (2017).

[8] Bossoufi, B., Ionita, S., Constantinescu, L., Alami Arroussi , H., El Ghamrasni, M. , \& Ihedrane, Y., "Managing voltage drops: a variable speed wind turbine connected to the grid", International Journal of Automation and Control , 11(1):15-34,(2017)

[9] Bossoufi, B., Karim ,M., Lagrioui ,A., Taoussi ,M.,Derouich ,A., “Observer backstepping control of DFIGGenerators for wind turbines variable-speed: FPGA-based implementation.” Renewable Energy (ELSIVER), 81: 903-917,( 2015)

[10] Amimeur ,H., Aouzellag,D., Abdessemed,R.,Ghedamsi, K.,"Sliding mode control of a dual-stator induction generator for wind energy conversion systems. ", International Journal of Electrical Power \& Energy Systems, 42(1):60-70, (2012)

[11] Ihedrane ,Y., EL Bekkali, C. , Bossoufi, B. , "Direct and indirect field oriented control of DFIG-generators for wind turbines variable-speed.', 14th International Multi-Conference on Systems, Signals \& Devices (SSD), Marrakech Morocco-, 28-31 (March 2017).

[12] Aouzellag,D., Ghedamsi, K., Berkouk,E.M., “ Network power flux control of a wind generator.", Renewable Energy, 34(3): 615-622,(2009).

[13] Bekakra,Y., Ben Attous, D., "DFIG sliding mode control fed by back-to-back PWM converter with DC-link voltage control for variable speed wind turbine," Frontiers in Energy, $8: 345-354$, (2014).

[14] MACHMOUM, M. et POITIERS,F.,"Sliding mode control of a variable speed wind energy conversion system with DFIG.,'Ecologic vehicles; renewable energies, MONACO,(March 2009).

[15] TAMAARAT ,A., "Modélisation et commande d'un système de conversion d'énergie éolienne à base d'une MADA.,", Phd.Thesis, Université Mohamed Khider,Biskra, (2015).

[16] Bregeault, V., "Quelques contributions à la théorie de la commande par modes glissants.', Phd.Thesis, Ecole Centrale de Nantes (ECN). (2010).

[17] Slotine, J. J., and W. Li. ,“Applied Nonlinear Control, Prentice-Hall, Englewood Cliffs, NJ, 1991.”, 461,Google Scholar (1998).

[18] Hashimoto, H., Yamamoto, H., Yanagisawa, S., \& Harashima, F. , "Brushless servo motor control using variable structure approach", IEEE Transactions on industry applications, 24(1), 160-170, (1988).

[19] HAMDI ,N., "Amélioration des performances des aérogénérateurs. ", Phd.Thesis, Universite Constantine I ,(2013).

[20] Fillipov,A.,"Differential equations with discontinuous right-hand side', Amer.Math.sco.Trans,(1960).

[21] Utkin ,V., "Sliding modes and their application in variable structure systems. ", Moscou: Mir,( 1978).

[22] Jerbi,L., Krichen,L., Ouali,A., "A fuzzy logic supervisor for active and reactive power control of a variable speed wind energy conversion system associated to a flywheel storage system, ", Electric power systems research, Elsevier , 79(6): 919-925, (2009).

[23] El Ouanjli, N., Derouich, A.,El Ghzizal, A.,El Mourabet ,Y., Bossoufi,B., Taoussi,M., "Contribution to the performance improvement of Doubly Fed Induction Machine functioning in motor mode by the DTC control", International Journal Power Electronics and Drive System , 8 (3): 1117-1127,(2017).

[24] N. El Ouanjli, et al., "High Performance Direct Torque Control of Doubly Fed using Fuzzy Logic," Gazi University Journal of Science, vol.31, No. 2, pp. 532-542, 2018. 


\section{BIOGRAPHIES OF AUTHORS}
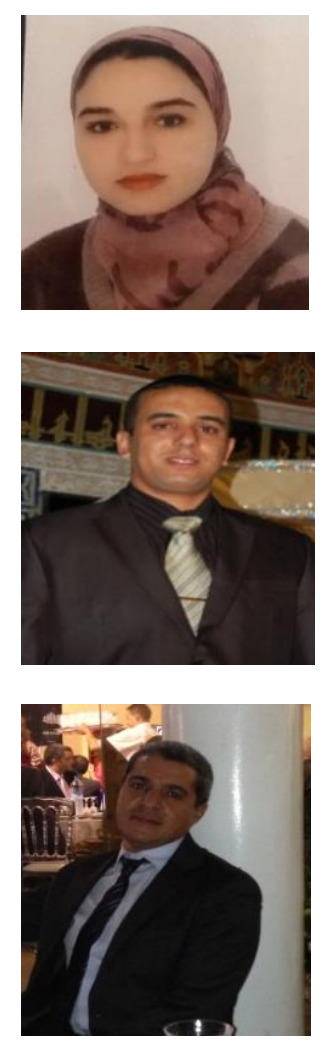

Yasmine IHEDRANE born December 26, 1991 at FES, Morocco, she obtained her master's degree in Engineering of Industrial Automated Systems at the Faculty of Sciences Dhar el Mahrez -FES- where he currently works, $\mathrm{PhD}$. graduate student in the same university and is a member laboratory LISTA. Her interests in machine control.

Badre BOSSOUFI was born in Fez city, Morocco, on May 21, 1985. He received the Ph.D. degree in Electrical Engineering from University Sidi Mohammed Ben Abdellah, Faculty of Sciences, Morocco and PhD. degree from University of Pitesti, Faculty of Electronics and Computer, Romanie and Montefiore Institute of electrical engineering, Luik, Belgium, in 2013. He was an Assistant Professor of Electrical Engineering, at the fHigher School of technologie, Oujda Morocco.His research interests include static converters, electrical motor drives, power electronics, Smart Grid, Renewable Energy and Artificial Intelligent.

Chakib EL BEKKALI was born in Fez city, Morocco, on March 19, 1965. He received the Ph.D degree in Signal processing University Sidi Mohammed Ben Abdellah, Faculty of Sciences. Professor of signal processing at faculty of science FES Morocco. director adjoint of laboratory LISTA. His research interests signal processing and automatic 